\title{
ANALISIS UNJUK KERJA ZERO FORCING EQUALIZER PADA SISTEM OFDM MIMO
}

\author{
R. A. Prayitno ${ }^{1}$, N.M.A.E.D.Wirastuti ${ }^{2}$, I.G.A.K.D.D. Hartawan ${ }^{3}$ \\ ${ }^{123}$ Program Studi Teknik Elektro, Fakultas Teknik, Universitas Udayana \\ Email: ryzkyajp@gmail.com ${ }^{\underline{1}}$, dewi.wirastuti@unud.ac.id ${ }^{2}$, igak.diafari@ee.unud.ac.id ${ }^{\underline{3}}$
}

\begin{abstract}
ABSTRAK
Jaringan wireless merupakan salah satu hal paling penting dalam perkembangan bidang telekomunikasi. Namun teknologi wireless yang ada saat ini belum mampu secara effisien untuk menciptakan data rate yang sangat tinggi karena sangat sensitif terhadap fading. Oleh sebab itu digunakanlah teknologi Orthogonal Frequency Division Multiplexing (OFDM) yang dikombinasikan dengan sistem transceiver MIMO (Multiple Input Multiple Output) untuk mendapatkan diversity gain yang lebih besar dan efisiensi bandwidth. Propagasi yang dilakukan pada sistem OFDM MIMO adalah propagasi multipath, maka untuk mengurangi Intersymbol Interference (ISI) digunakan Zero Forcing (ZF) equalizer yang bekerja dengan cara menggabungkan respon kanal dan respon equalizer itu sendiri sehingga meniadakan ISI. Penelitian ini bertujuan untuk mengetahui pengaruh Zero Forcing Equalizer pada sistem OFDM MIMO melalui kanal rayleigh fading dan hasilnya akan dibandingkan dengan sistem OFDM MIMO STBC. Metode penelitian yang digunakan adalah dengan simulasi menggunakan perangkat lunak MatLab R2015a. Hasil simulasi yang diperoleh menunjukkan bahwa performa sistem OFDM MIMO ZF lebih buruk daripada sistem OFDM MIMO STBC di semua simulasi yang dilakukan yaitu simulasi BER vs EbNo, simulasi eye diagram, dan simulasi diagram konstelasi. Sistem OFDM MIMO ZF membutuhkan nilai Eb/No lebih dari 25 dB untuk mencapai BER $10^{-4}$ sedangkan sistem OFDM MIMO STBC hanya memerlukan nilai Eb/No sebesar 10,5 dB untuk mencapai BER $10^{-4}$. Pola mata yang dihasilkan sistem OFDM MIMO ZF lebih tertutup dan penyebaran sinyal konstelasi menjauhi titik ideal, sedangkan sistem OFDM MIMO STBC menampilkan pola mata yang lebih terbuka serta penyebaran sinyal konstelasinya lebih rapat mendekati titik ideal. Hal tersebut menandakan ISI lebih banyak terjadi pada sistem OFDM MIMO ZF dibandingkan dengan sistem OFDM MIMO STBC.
\end{abstract}

Kata Kunci : Eye diagram, ISI, MIMO, OFDM, ZF

\section{ABSTRACT}

Wireless network is one of the most important things in the development of telecommunication. However, the existing wireless technology has not been able to efficiently create a very high data rate because it was very sensitive to fading. Therefore, Orthogonal Frequency Division Multiplexing (OFDM) technology combined with MIMO (Multiple Input Multiple Output) transceiver system was used to gain more diversity and bandwidth efficiency. The propagation performed on the OFDM MIMO system was multipath propagation. To reduce Intersymbol Interference (ISI) was used Zero Forcing (ZF) equalizer which works by combining channel response and equalizer response itself to eliminate ISI. This study aims to determine the effect of Zero Forcing Equalizer on OFDM MIMO system using rayleigh fading channel and compared the result with OFDM MIMO STBC system. The research method used was simulation using MatLab R2015a. The simulation results showed that the performance of OFDM MIMO ZF system was worse than OFDM MIMO STBC system i.e BER vs EbNo simulation, eye diagram simulation, and constellation diagram simulation. The OFDM MIMO ZF system was required an Eb / No value more than $25 \mathrm{~dB}$ to achieve BER $10^{-4}$ while the OFDM MIMO STBC system only required an $E b / N o$ value of $10.5 \mathrm{~dB}$ to achieve BER $10^{-4}$. The eye pattern generated by the OFDM MIMO ZF system was more closed and the dispersion of constellation signals away from the ideal point while OFDM MIMO STBC system displayed a more open eye pattern and the dispersion of its constellation signal closer to the ideal point. It indicated more ISI occurs in the OFDM MIMO ZF system than that in OFDM MIMO STBC system.

Keywords: Eye diagram, ISI, MIMO, OFDM, ZF 


\section{PENDAHULUAN}

Teknologi Orthogonal Frequency Division Multiplexing (OFDM) merupakan salah satu teknologi yang telah luas digunakan dan merupakan salah satu teknologi komunikasi yang sangat menjanjikan. Teknologi ini memiliki banyak keunggulan diantaranya efisiensi bandwidth dan kompleksitas komputasi yang kecil. Teknologi OFDM ini dapat dikombinasikan dengan sistem transceiver MIMO (Multiple Input Multiple Output) untuk mendapatkan diversity gain yang lebih besar serta peningkatan kapasitas sistem [1].

Teknik MIMO menggunakan lebih dari satu input pada transmitter dan juga lebih dari satu output pada receiver. Tujuan utama penggunaan sistem kombinasi OFDM MIMO ini adalah untuk mendapatkan data rate dan performa sistem yang tinggi. Kombinasi sistem OFDM MIMO ini juga merupakan kombinasi yang sangat menjanjikan mengingat sistem OFDM mampu menopang lebih banyak antena dikarenakan sistem ini mampu menyederhanakan ekualisasi pada sistem MIMO [1].

Propagasi multipath mengakibatkan terjadinya perbedaan waktu yang akan menyebabkan terjadinya intersymbol interference (ISI). Salah satu cara menangani ISI adalah dengan menambahkan equalizer pada sisi penerima. Zero forcing (ZF) equalizer adalah salah satu equalizer yang paling mudah dibuat dan diimplementasikan yang akan membuat efek ISI menjadi nol [2].

Untuk mengetahui sistem yang memberikan performansi terbaik maka dilakukan simulasi unjuk kerja untuk membandingkan sistem OFDM MIMO ZF dan OFDM MIMO STBC yang masingmasing menggunakan kanal rayleigh fading.

\section{KAJIAN PUSTAKA}

\subsection{Orthogonal Frequency Division Multiplexing (OFDM)}

OFDM adalah sebuah teknik transmisi dimana beberapa buah frekuensi dikirim saling tegak lurus (orthogonal). Aliran data dengan kecepatan tinggi akan dibagi ke dalam aliran data kecepatan rendah kemudian dikirimkan melalui beberapa subcarrier. Subcarrier ini disusun saling overlapping dan diatur jaraknya agar memiliki sifat yang orthogonal dan tidak menimbulkan efek Inter Carrier Interference
(ICI) sehingga dapat menghemat bandwidth [2]. Sistem OFDM sederhana ditunjukkan pada Gambar 1.

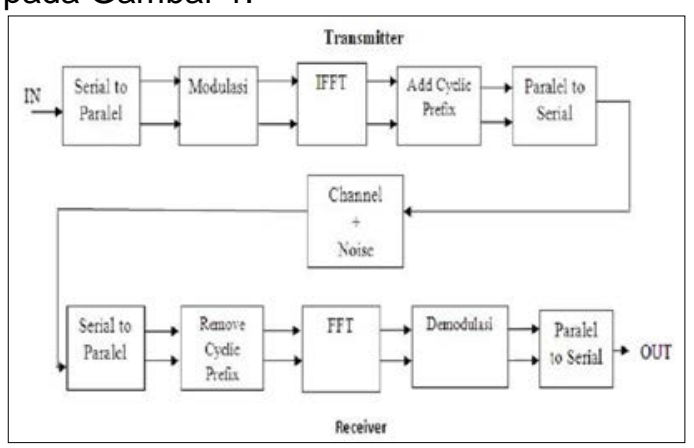

Gambar 1. Blok Diagram Sistem OFDM Sederhana

\subsection{Multiple Input Multiple Output (MIMO)}

Prinsip kerja teknik MIMO adalah memperbanyak sinyal informasi yang dipancarkan yaitu dengan mempergunakan multi antena pada sisi pengirim dan penerima untuk meningkatkan kemampuan komunikasi dan mengurangi error yang dapat terjadi akibat kanal transmisi. Dengan demikian akan menyebabkan peningkatkan efisiensi spektrum dan perbaikan pada kualitas saluran [2]. Skema teknik MIMO dapat dilihat pada Gambar 2.

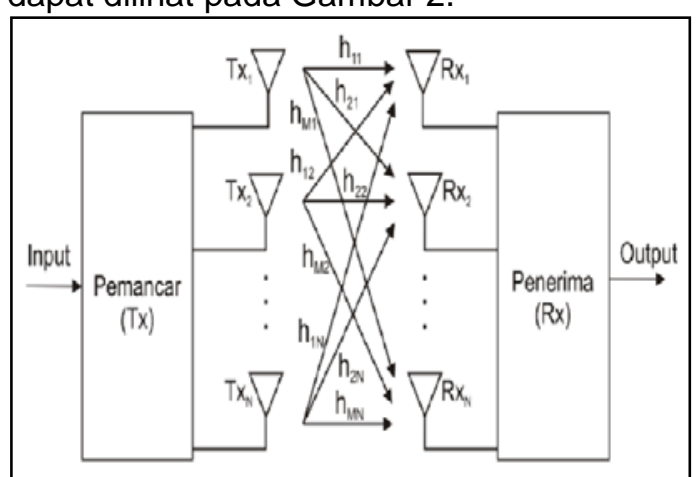

Gambar 2. Skema Teknik MIMO

\subsection{Equalizer Zero Forcing (ZF)}

Ada dua jenis equalizer linear, salah satunya adalah equalizer zero forcing. Equalizer ini dapat menghilangkan semua ISI namun juga akan menyebabkan peningkatan noise. Sinyal input yang diterima zero forcing receiver dapat direpresentasikan berdasarkan sinyal diskrit sistem gabungan [6] :

$$
f(t)=h(t) * g *(-t)
$$

sebagai :

$$
Y(z)=D(z) F(z)+N(z)
$$


Dimana :

$f(t) \quad=$ frekwensi

$h(t) \quad=$ respon impuls kanal

$g *(-t)=$ matched filter

$N(z) \quad=$ power spectrum dari white noise setelah melewati matched filter $G *(1 / z)$ dan equalizer $H_{e q}(z)$, serta [6] :

$$
F(z)=H(z) G *(1 / z)
$$

Zero forcing equalizer menghapus semua ISI pada respon gabungan $f(t)$. Ini dibuktikan pada Persamaan 2 karena telah memenuhi persamaan [6]:

$$
H_{z f}(z)=1 / F(z)
$$

Dimana $\quad F(z)$ adalah frekwensi komposit, dan $H(z)$ adalah kanal komposit [6].

\subsection{Space Time Block Code (STBC)}

STBC merupakan suatu teknik pengkodean sinyal dimana sinyal-sinyal akan disusun menjadi beberapa simbol dalam satu ruang dan dikirim menggunakan teknik diversity ruang dalam beberapa periode waktu. Teknik STBC diterapkan dengan menggunakan diversitas antena atau perancangan orthogonal. Sebelum dipancarkan, setiap dua simbol data akan dikirim dalam dua periode simbol, namun pada antena kedua urutan simbolnya dibalik, dikonjugasi, dan salah satunya dinegatifkan. Tujuannya adalah untuk memudahkan pemisahan kedua simbol pada sisi penerima [3].

\section{METODE PENELITIAN}

\subsection{Parameter Simulasi}

Parameter simulasi yang akan digunakan dalam penelitian ini dapat dilihat pada Tabel 1.

\subsection{Pemodelan Sistem}

Pemodelan simulasi sistem OFDM MIMO ZF dan OFDM MIMO STBC pada kanal Rayleigh dapat dilihat pada Gambar 3 dan Gambar 4. Masing-masing simulasi dilakukan untuk mengetahui perbedaan nilai BER vs Eb/No yang dihasilkan dalam bentuk grafik, perbedaan pola mata pada eye diagram, serta perbedaan sebaran sinyal pada diagram konstelasi.
Tabel 1. Parameter Simulasi

\begin{tabular}{|l|c|}
\hline \multicolumn{1}{|c|}{ Parameter } & $\begin{array}{c}\text { Nilai yang } \\
\text { digunakan }\end{array}$ \\
\hline Panjang simbol OFDM & 64 \\
\hline Jumlah Subcarrier & 52 \\
\hline Jumlah simbol FFT & 64 \\
\hline Tipe modulasi & QPSK \\
\hline Kanal & Rayleigh fading \\
\hline Zero padding & 12 \\
\hline Guard periode type & Cyclic prefix \\
\hline Jumlah Cyclic prefix & 0.8 ss \\
\hline Periode cyclic prefix & $0-25 \mathrm{~dB}$ \\
\hline Nilai Eb/No (dB) & 10 \\
\hline Filter span & 1 \\
\hline Sampel per simbol & 100.000 bit \\
\hline $\begin{array}{l}\text { Jumlah bit yang di } \\
\text { inputkan }\end{array}$
\end{tabular}

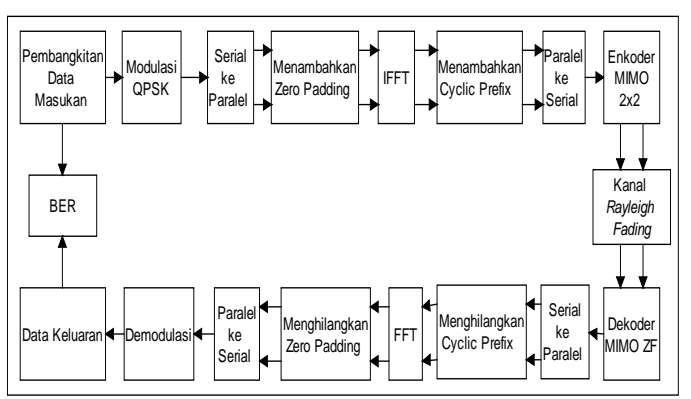

Gambar 3. Pemodelan simulasi OFDM MIMO ZF

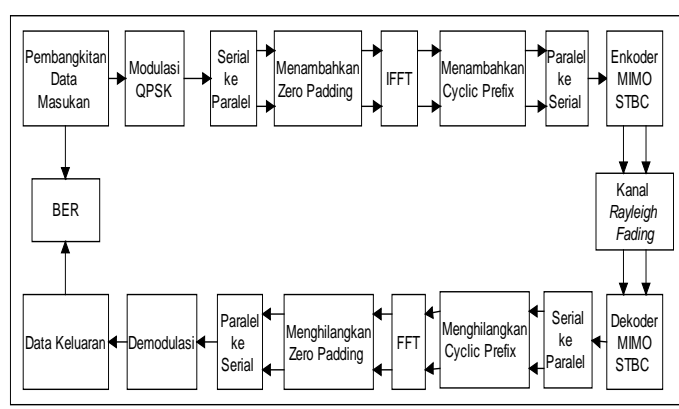

Gambar 4. Pemodelan simulasi OFDM MIMO STBC

Berdasarkan pada Gambar 3 dan Gambar 4, simulasi dimulai dari blok pembangkitan data masukan dimana data dimasukan secara acak (random) dalam bentuk biner "1" dan "0" sebanyak 100.000 bit. 
Kemudian pada pemancar OFDM terdapat beberapa tahapan yang dimulai dari blok modulasi dimana dalam penelitian ini menggunakan modulasi QPSK. Sebelum dimodulasi, data bit masukan akan di mapping terlebih dahulu yang akan menghasilkan 2 bit per simbol. Sehingga yang awalnya ada jumlah bit dari 1 sampai 100.000 akan menghasilkan jumlah simbol sebanyak 50.000 [5].

Kemudian simbol yang telah dimodulasi diubah dari deretan serial ke parallel. Selanjutnya penambahan Zero Padding bertujuan untuk menambah panjang sinyal OFDM. Jumlah zero padding yang digunakan adalah 14, sehingga setiap simbol OFDM memiliki ukuran 64 baris. Lalu pada blok Inverse Fast Fourier Transfrom (IFFT) bertujuan untuk mengubah aliran simbol dari domain frekuensi ke domain waktu dengan ukuan 64 sesuai dengan aliran simbol yang memiliki 64 baris dan dalam bentuk aliran data parallel. Tahapan selanjutnya adalah penambahan guard interval (GI) berupa cyclic prefix (CP) untuk mencegah Inter Symbol Interference (ISI) dengan panjang cyclic prefix sebesar 16 baris sehingga panjang simbol OFDM akan berubah menjadi 80 baris. Sebelum masuk ke dekoder, simbol OFDM di ubah dari parallel ke serial terlebih dahulu [4].

Perbedaan dari kedua sistem ini adalah pada blok dekoder dan enkoder, dimana pada sistem OFDM MIMO ZF menggunakan enkoder MIMO $2 \times 2$ dan dekoder MIMO ZF yang dapat dilihat pada Gambar 3, sedangkan sistem OFDM MIMO STBC menggunakan enkoder MIMO STBC $2 \times 2$ serta dekoder MIMO STBC seperti yang terlihat pada Gambar 4.

Dari blok enkoder sinyal dikirim dari pemancar OFDM dan melalui kanal rayleigh fading, kemudian akan tiba di sisi penerima pada blok dekoder untuk kemudian berlajut kebalikan dari proses saat di sisi pemancar OFDM tadi hingga menghasilkan data bit keluaran untuk menghitung error yang terjadi pada blok BER.

Selain menghasilkan grafik BER vs $\mathrm{Eb} / \mathrm{No}$, simulasi ini juga akan menghasilkan eye diagram dan diagram konstelasi untuk kemudian dianalisa perbandingannya pada kedua sistem.

\section{HASIL DAN PEMBAHASAN}

\subsection{Hasil Simulasi}

Hasil simulasi yang dilakukan pada sistem OFDM MIMO ZF dan OFDM MIMO STBC adalah sebagai berikut:

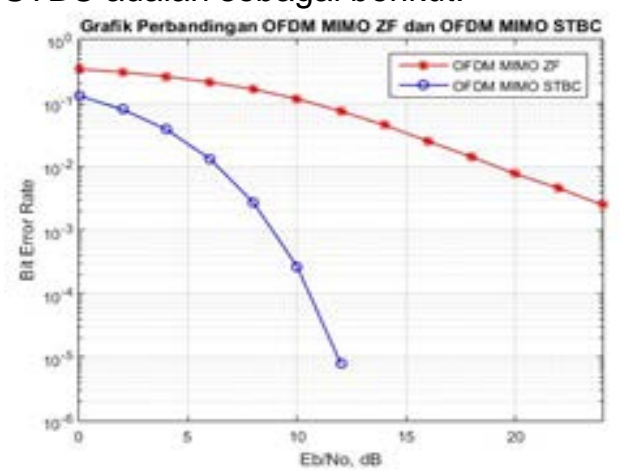

Gambar 5. Perbandingan BER vs Eb/No Sistem OFDM MIMO ZF dan OFDM MIMO STBC
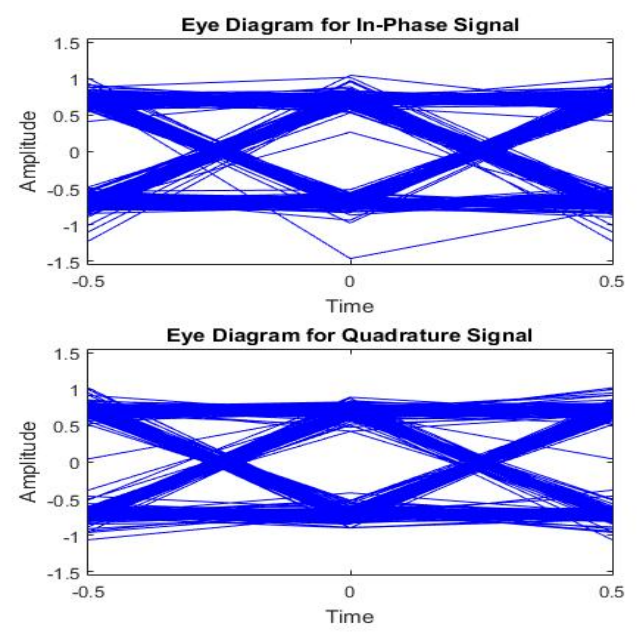

Gambar 6. Eye Diagram Sistem OFDM MIMO ZF

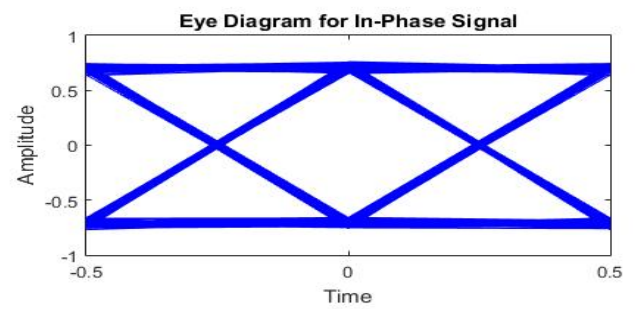

Eye Diagram for Quadrature Signal

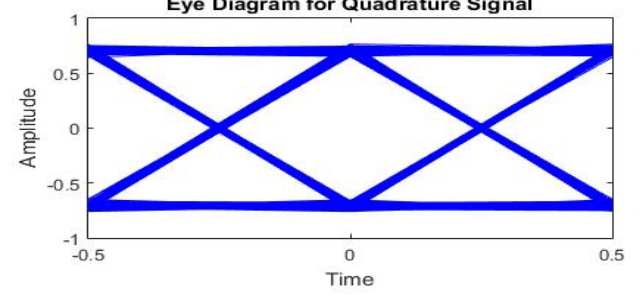

Gambar 7. Eye Diagram Sistem OFDM MIMO STBC 


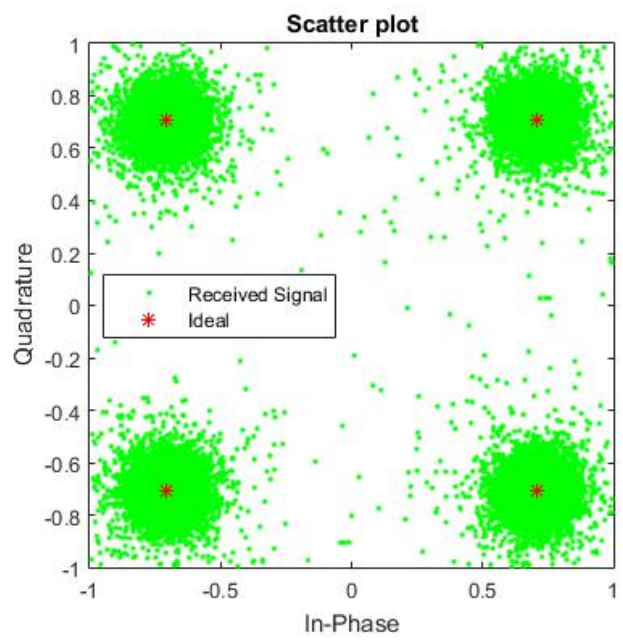

Gambar 8. Diagram Konstelasi Sistem OFDM MIMO ZF

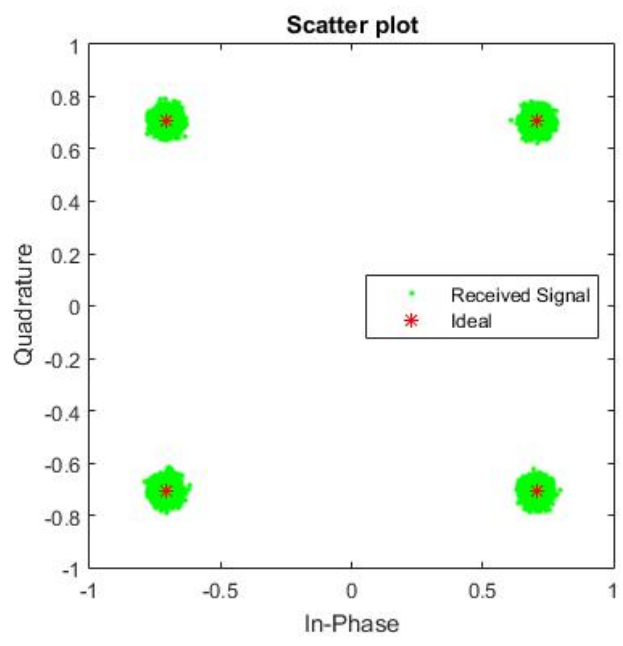

Gambar 9. Diagram Konstelasi Sistem OFDM MIMO STBC

\subsection{Pembahasan Hasil Simulasi}

Hasil dari simulasi yang dilakukan berupa grafik dan gambar diagram perbandingan antara kedua jenis sistem yaitu OFDM MIMO ZF dan OFDM MIMO STBC yang dilihat dari :

1. Perbandingan BER vs Eb/No (Gambar 5).

2. Perbandingan eye diagram (Gambar 6 dan Gambar 7).

3. Perbandingan diagram konstelasi (Gambar 8 dan Gambar 9).

\subsubsection{Perbandingan BER vs Eb/No}

Hasil dari simulasi menunjukkan perbandingan nilai BER vs Eb/No dari sistem OFDM MIMO ZF dan OFDM MIMO
STBC dalam bentuk grafik yang dapat dilihat pada Gambar 5.

Gambar 5 menunjukkan perbandingan nilai BER vs Eb/No dari sistem OFDM MIMO ZF dan OFDM MIMO STBC pada kanal Rayleigh Fading. Untuk mencapai nilai BER $10^{-4}$ pada sistem OFDM MIMO ZF membutuhkkan Eb/No lebih dari $25 \mathrm{~dB}$ sedangkan sistem OFDM MIMO STBC hanya membutuhkan Eb/No sebesar 10,5 dB.

\subsubsection{Perbandingan Eye Diagram}

Eye diagram dari hasil simulasi sistem OFDM MIMO ZF dan OFDM MIMO STBC melalui kanal Rayleigh Fading dapat dilihat pada Gambar 6 dan Gambar 7.

Dari Gambar 6 terlihat pola mata pada sistem OFDM MIMO ZF lebih tertutup dan tebal dibandingkan sistem OFDM MIMO STBC yang pola matanya terlihat lebih terbuka dan tipis pada Gambar 7. Hal tersebut menunjukkan bahwa ISI lebih banyak terjadi pada sistem OFDM MIMO ZF yang menyebabkan simbol-simbol yang dikirim dalam waktu yang berbeda mengalami interferensi satu dengan lainnya sehingga garis-garis yang membentuk pola mata menjadi lebih tebal dan terlihat seperti mata yang lebih tertutup.

\subsubsection{Perbandingan Diagram Konstelasi}

Simulasi ini dilakukan pada sistem OFDM MIMO STBC dan sistem OFDM MIMO ZF melalui kanal Rayleigh Fading. Hasil simulasi diagram konstelasi dari masing-masing sistem dapat dilihat pada Gambar 8 dan Gambar 9.

Dari Gambar 8 dan Gambar 9 terlihat plot sinyal dari sistem OFDM MIMO ZF menunjukkan sinyal menyebar sangat jauh dari titik ideal, sedangkan pada sistem OFDM MIMO STBC sebaran masingmasing sinyal saling rapat satu dengan lainnya dan mendekati titik ideal. Hal tersebut menunjukkan bahwa ISI lebih banyak terjadi pada sistem OFDM MIMO ZF daripada sistem OFDM MIMO STBC sehingga menyebabkan plot sinyal yang 
menyebar dan tidak rapat serta banyak sinyal yang berada jauh dari titik ideal.

\section{Simpulan}

Berdasarkan hasil dan pembahasan yang telah diuraikan sebelumnya, dapat diambil simpulan sebagai berikut :

1. Hasil simulasi menunjukkan bahwa performa sistem OFDM MIMO ZF lebih buruk dari sistem OFDM MIMO STBC di semua simulasi yaitu BER vs Eb/No, eye diagram, maupun diagram konstelasi.

2. OFDM MIMO ZF membutuhkan nilai Eb/No lebih dari 25 dB untuk mencapai BER $10^{-4}$ sedangkan sistem OFDM MIMO STBC hanya memerlukan Eb/No sebesar 10,5 dB.

3. Sistem OFDM MIMO ZF menghasilkan pola mata yang lebih tertutup dan tebal, serta konstelasi sinyal yang lebih tidak rapat serta menjauhi titik ideal dibanginkan dengan OFDM MIMO STBC. Ini menandakan ISI lebih banyak terjadi pada OFDM MIMO ZF dan menyebabkan simbol yang dikirim dalam waktu yang berbeda mengalami interferensi antara satu simbol dengan lainnya.

\section{Daftar Pustaka}

[1] Kaur, N. and Kansal, L., "Performance Comparison of MIMO Systems over AWGN and Rayleigh Channels with Zero Forcing Receivers", Global Journals, vol. 13, issue 1, ISSN: 22494596, 2013.

[2] Purwanto, T. B., "Analisis Unjuk Kerja Teknik MIMO STBC Pada Sistem Orthogonal Frequency Division Multiplexing". Jurnal IImiah Spektrum, Vol. 2, No. 2, Februari 2016.

[3] Gunantara N., "Analisis Unjuk Kerja Teknik Pengkodean STBC dan Waterfilling Pada Sistem D-MIMO", Jurnal Teknik Elektro, Vol. 7, No. 2 Juli-Desember 2008.

[4] Yuniari, N. P. E. A., "Perbandingan Performansi Sistem MC-SS MIMO dengan OFDM MIMO", Majalah IImiah Teknologi Elektro, Vol. 15, No. 2, Desember 2016.

[5] Amillia, F., Erpan, M., "Analisis Perbandingan Kinerja Teknik Modulasi BPSK dan QPSK Menggunakan Kanal
Flat Slow Fading Pada Sistem CDMA", Jurnal Sains, Vol. 12, No. 2, Juni 2015.

[6] Goldsmith, A., "Wireless Communications", edisi 1, Cambridge University Press, Agustus 2005 : 311314. 